\title{
Microbiology of Oral Biofilm-Dependent Diseases: Have We Made Significant Progress to Understand and Treat These Diseases?
}

\author{
Ana Paula Vieira Colombo • Renata Martins do Souto • \\ Carina Maciel da Silva-Boghossian • Rachel Miranda • \\ Talita Gomes Baêta Lourenço
}

Published online: 24 December 2014

(C) Springer International Publishing AG 2014

\begin{abstract}
The oral microbiome plays a crucial role in the establishment and maintenance of oral health. Major disturbances in the interactions between this microbiome, the microenvironment, and the host may lead to the development of oral diseases. A large proportion of infectious diseases that affect humans are caused by organisms living in biofilms. This is also the case for oral infections such as dental caries, periodontal diseases, and endodontic and fungal infections. In this review, new concepts regarding the role of the oral biofilm in the etiopathogenesis of these diseases are presented, and a more ecological view of pathogenic communities as causative agents of oral diseases is discussed. We believe that a better understanding of oral biofilm physiology and ecology will provide insight for the development of new cost-effective diagnostic tools, as well as preventive and therapeutic strategies for the management of these infections.
\end{abstract}

Keywords Oral microbiome $\cdot$ Oral microbiota $\cdot$ Dental biofilm · Dental plaque $\cdot$ Caries $\cdot$ Periodontal diseases . Endodontic infections

This article is part of the Topical Collection on Microbiology

A. P. V. Colombo • R. M. do Souto • C. M. da Silva-Boghossian • R. Miranda • T. G. B. Lourenço

Institute of Microbiology, Federal University of Rio de Janeiro, Rio de Janeiro, Brazil

C. M. da Silva-Boghossian

UNIGRANRIO, Rio de Janeiro, Brazil

A. P. V. Colombo $(\square)$

UFRJ/CCS, Instituto de Microbiologia Paulo de Góes, Bloco I, lab.

I2-03, Av. Carlos Chagas Filho, 373 Cidade Universitária,

Rio de Janeiro, RJ, Brasil CEP 21941-902

e-mail: apcolombo@micro.ufrj.br

\section{Introduction}

Microorganisms are everywhere whether you like it or not. It is estimated that there are approximately $5 \times 10^{30}$ bacteria on the planet [1], a number that exceeds all living animals and plants. The first living organisms to emerge from a common ancestor about 3 billion years ago were bacteria, whereas mammals only evolved in the past 65 million years. Much later, bacteria co-evolved and became adapted to the human host by developing fitness factors [2]. In fact, the human body is inhabited by at least ten times more bacteria than the number of human cells. So, how human are we? One may even say that microorganisms are a part of us, an extension of our biological identity.

According to what we have learned from the 'Golden Age' of Microbiology, when we think of microbes, in particular bacteria, we think of illness or infection. However, our thinking of microorganisms as agents causing diseases is changing drastically as we start to understand the crucial role of bacteria in maintaining the homeostasis of the human organism as well as the entire biosphere. Since the beginning of the Human Microbiome Project, an extraordinary amount of data regarding the composition and function of the microbiome living in or on our body have been produced [3*•]. These data have indicated that knowledge of our relationships with our indigenous microbiota is primordial for us to understand human health and disease. This review presents recent findings on the normal oral microbiome (and mycobiome), as well as the microbiome/mycobiome associated with caries, periodontal diseases, and fungal and endodontic infections. The structure, function, and virulence of the oral biofilm related to oral health and diseases are also reviewed. Finally, novel and conventional strategies of personalized therapies for treating oral biofilm-related diseases are discussed. 


\section{Human Oral Microbiome in Health and Disease}

The human microbiome has been shown to contribute to human genetic composition and physiology, providing fea-

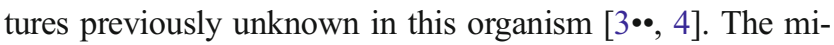
croorganisms of this microbiome are part of the biology of the human body, performing important functions such as protection against colonization by exogenous pathogens, processing of nutrients, regulation of lipid metabolism, induction of angiogenesis, and the development of intestinal mucosa and the immune system [5-8]. However, for reasons not entirely known, some of these members of the resident microbiota may develop a pathogenic profile and cause diseases.

Recent data from metagenomic studies have revealed that the various habitats of the human body have unique ecosystems with distinct microbiomes and metagenomes [9, 10]. Interestingly, there is a marked variability in the composition of the microbiome in different anatomical regions of the same individual as well as inter-individual variability in the microbiome of the same anatomical region [11]. On the other hand, a temporal stability of the microbiome from different habitats of an individual has been reported [12]. Since each individual has a unique microbiome playing a specific role in the etiology of diseases of the human organism, these diseases may manifest and progress differently among people, reinforcing the need for a more personalized medicine for the maintenance of human health.

The impact of the microbiome in human health has been emphasized by remarkable data highlighting the association between the intestinal microbiota and various human diseases such as obesity, cancer, gastrointestinal inflammatory diseases, cardiovascular diseases, autism, and psoriasis, among others [5, 13-15]. Based on this concept, strategies for restoring the beneficial and competitive resident microbiota, including the use of probiotics and prebiotics, have been proposed as alternative therapies for several diseases [16].

Oral infectious diseases are among the most common infections in humans [17]. The oral cavity is a highly dynamic environment that communicates the human body to the external environment. The different habitats in the oral cavity allowed the existence of distinct ecological niches that promote colonization of a wide variety of microorganisms [18••]. These microbial communities are composed typically of commensal species that are essential in maintaining the host's oral health. However, as in other microbial infections of the human body, dysbiosis of this oral microbiome caused by a large variety of local, environmental, behavioral, host, and genetic factors, and by mechanisms not totally understood, may lead to the development of oral diseases such as caries, periodontal diseases, endodontic infections, tonsillitis, and alveolitis [19-21].

With the development of faster and more accurate techniques of molecular taxonomy [22], and the creation of databases of oral microorganisms [23], more complete and detailed analysis of complex oral microbial communities and their relationship with the human body can be obtained in a short period of time. Classical studies using cultural methods and microscopy identified approximately 300 bacterial species in the oral cavity [24]. More recent data obtained by nextgeneration molecular techniques have demonstrated that over 700 microbial species can be detected in the oral cavity, and about half of these species are not yet cultivated microorganisms [25-27]. Overall, genera such as Streptococcus, Actinomyces, Veillonella, Neisseria, Prevotella, Gemella, Haemophilus, Lactobacillus, Capnocytophaga, Staphylococcus, Fusobacterium and Propionibacterium are predominant in most of the habitats $[18 \bullet \bullet, 25,26]$. The dental biofilms specifically comprise high proportions of streptococci, actinomycetes, Prevotella, Porphyromonas, Tannerella, and Fusobacterium, although these proportions may vary according to the presence and severity of dental diseases [28]. A large body of evidence generated by studies of the human microbiome provides support to a more ecological holistic concept of pathogenic or beneficial microbial consortia instead of the single pathogen or health-associated species etiology. With that in mind, a deeper knowledge of the composition and function of the oral microbiome, and its relationship with the host and microenvironment, is fundamental for us to comprehend the role of these microorganisms in health and disease, and to design more effective therapeutic strategies.

\section{Oral Biofilm: The Dental Plaque}

The term 'biofilm' was described in 1978 [29] and is currently defined as a sessile microbial population composed of cells irreversibly adhered to a substratum, to an interface or between them, enclosed in a matrix of extracellular polymeric substances (EPS) produced by themselves, and which present a modified phenotype, regarding growth rate and gene transcription [30]. EPS affects the features of the microbial communities, such as mass transfer, surface characteristics, adsorption capability and stability, and is used as a source of nutrients [30]. Biofilms are considered a different growth phase, alternative to planktonic cells, and can be developed by bacteria on a number of different surfaces [31]. The biofilm is an effective survival organization that protects the resident microorganisms from exogenous, potentially harmful factors, and permits cooperative interactions between cells of the same or different species. Moreover, biofilms allow bacteria to develop resistance to bacteriophage, host immune responses, antibiotics, and mechanical removal [31].

Dental plaque is a classical example of a complex microbial community growing on teeth and/or implant surfaces in a biofilm structure. It contributes to host oral homeostasis but it also has the potential to cause disease [28, 32]. Its composition 
is very diverse, as well as its structure and thickness on different oral surfaces presenting distinct physical and biological properties [32]. Dental plaque has been intensively studied as model systems for bacterial adhesion, aggregation, coaggregation, biofilm development, and resistance to antimicrobials [33]. Dental plaque is broadly classified as supragingival plaque, found at or above the gingival margin, and subgingival plaque present below the gingival margin, between the tooth and the gingival sulcular tissue. Supragingival plaque typically demonstrates a stratified organization of bacterial morphotypes. Gram-positive cocci and short rods predominate at the tooth surface, whereas Gramnegative rods and filaments, as well as spirochetes, predominate in the outer surface of the mature plaque mass [34]. The gingival crevice or periodontal pocket area is bathed by the flow of the crevicular fluid, which contains many substances, particularly proteins used as nutrients by bacteria [35]. In addition, inflammatory cells and mediators have considerable influence on the establishment and composition of the subgingival biofilm [35]. The tooth-associated plaque is characterized by Gram-positive cocci and rods, whereas the apical border of the plaque mass is separated from the junctional epithelium by a layer of host leukocytes, and an increased proportion of Gram-negative rods. The transition from Grampositive to Gram-negative microorganisms during the structural development of dental plaque is paralleled by physiologic changes in the microenvironment [33]. Early colonizers such as streptococci and Actinomyces spp. use oxygen and lower the reduction-oxidation potential of the environment, favoring the growth of anaerobic species [28].

Dental plaque constitution is defined by regulatory factors such as co-aggregation, quorum sensing, inhibitory factors, genetic exchange, and metabolic communication [36]. One of the most important mechanisms in dental biofilm formation is co-aggregation, which can be defined as specific cell-to-cell interactions that occur between distinct bacterial cells [32]. Co-aggregation among oral bacteria contributes to bacterial colonization, metabolic communication, and genetic exchange among bacteria, given that each microorganism can easily access a neighboring bacterial cell and its metabolites $[36,37]$. Some of the functions of biofilms depend on the ability of the bacteria to communicate with one another. Quorum sensing in a microbial biofilm requires the regulation of specific genes by signaling molecules that mediate intercellular communication [38]. Quorum sensing is dependent on cell density and influences various functions such as virulence, acid tolerance, and biofilm formation. Autoinducer-2 (AI-2) is one of the most well-known signaling molecules associated with quorum sensing. In $S$. gordonii for instance, AI-2 is responsible for biofilm formation and carbohydrate metabolism [39]. Genetic exchange among bacterial cells is also facilitated by the closely packed environment in biofilm communities, and is very important for bacterial evolution.
Conjugative mobile elements such as the transposon Tn916 and its derivative are very common in oral bacteria [40]. Moreover, bacteria inhabiting the oral biofilm may function as reservoirs of transferable conjugative plasmids carrying antibiotic resistance [41].

Depending on the predominance of specific ecological determinants, and behavioral and host-related factors, the dental biofilm may acquire a healthy, cariogenic and/or periodonto-pathogenic profile. Thus, the composition and function of the dental biofilm are major features that will determine oral health stability or the onset and progression of these infections.

\section{Cariogenic Biofilm}

Dental caries is the most prevalent biofilm-associated oral infection worldwide [17, 42]. This disease affects primarily children but also a large number of adults, deciduous and permanent teeth, and coronal as well as root surfaces [42]. Dental caries is still a major public health problem in developing and underdeveloped countries, having a significant negative impact on the quality of life of millions of people [43]. Strategies for caries control have markedly reduced the prevalence and incidence of dental caries in developed countries. Nevertheless, a significant increase in the global prevalence of dental caries has been reported [44].

Classical studies have elegantly demonstrated that caries is not only a bacterial infection but also a transmissible disease [45-48]. Although caries has a primary bacterial etiology, it is a multifactorial disease, and important modulating factors, including diet, host (teeth, saliva, mucosal immunity), social-economic conditions, and time, play a role in the initiation and progression of the disease [49].

The pathogenicity of the cariogenic biofilm is related to the presence of bacteria capable of producing high quantities of organic acids by fermenting several carbohydrates, even in the presence of a very low $\mathrm{pH}$ microenvironment (acid tolerance). These cariogenic microorganisms also have the ability to produce complex exopolysaccharide polymers that provide better and stronger adhesion on the tooth surface, as well as glycogen-like intracellular polysaccharides used as a reserve of carbohydrates [50].

The acquisition of microorganisms that colonize the oral cavity takes place at birth, and the main sources of vertical and horizontal transmission of these species by saliva are the mother and people from the child's environment, respectively. Thus, transmission occurs all the time, but only after the emergence of teeth in the mouth are potentially cariogenic species able to colonize [46-48]. In fact, early colonization by cariogenic bacteria is associated with high caries activity in childhood [51]. These cariogenic species are currently believed to be members of the normal oral microbiota [52], 
and are widely distributed in the population, including cariesfree and caries-active individuals [53].

There has been a long debate regarding the possible hypothesis for the etiology of dental caries. The 'non-specific plaque hypothesis' states that dental caries is an outcome of the overall activity of the total dental biofilm microbiota [54]. In contrast, the 'specific plaque hypothesis' proposes that only a few specific microorganisms present within the complex oral microbiota are involved in the disease [55]. Based on this hypothesis, considerable evidence has identifed the streptococci mutans (Streptococcus mutans and Streptococcus sobrinus) as the main causative agents of dental caries in humans [56]. Lactobacilli are also acidogenic and aciduric microorganisms that have been associated with advanced caries lesions, being involved in the progression of the disease [57], whereas Actinomyces species have been linked to root surface caries [58].

With the introduction of culture-independent techniques, researchers have demonstrated that the etiopathogenesis of dental caries involves a much more diverse and complex microbiota, and several microorganisms, including novel taxa, have been indicated as potential contributors to caries [59-61]. Of interest, different bacterial profiles were observed depending on the stage of caries development, and a reduced bacterial diversity was observed in the microbiota of advanced dentin lesions [62]. These data support the 'ecological plaque hypothesis' [63] which states that caries is a result of a shift in the homeostatic balance of the resident microbiota due to local environmental changes which will favor the outgrowth of more cariogenic species initially present in low numbers.

Traditional approaches for caries prevention include oral health education, diet counseling, chemical and mechanical control of biofilm, use of selants, fluorides and antimicrobial agents. Although most of these methods are effective, economic, behavioral, and cultural factors may interfere with the efficacy of these therapies in different individuals or populations [64]. Therefore, alternative ecological preventive and therapeutic strategies focusing on the restoration of a healthassociated ecosystem and not solely on the killing of specific pathogens have been proposed for combating dental caries. These interventions should be able to change environmental factors and disrupt bacterial community fitness that favors the predominance of more cariogenic microorganisms [65].

In replacement therapy (or probiotic therapy), the mutant strain of S. mutans BCS3-L1 lacks the lactate dehydrogenase gene, being unable to produce lactic acid from carbohydrate fermentation. Because this strain produces high amounts of mutacin 1140, a lantibiotic with antimicrobial activity against other strains of $S$. mutans, it is able to dislocate the wild-type strain and colonize its habitat. Some advantages of this ecological method are the lifelong protection, lack of risks, and no need for patient compliance [66]. Other investigations have explored the potential role for probiotic lactobacilli and bifidobacteria to modulate the oral microbial ecology [67]. Data have indicated that regular intake of milk supplemented with probiotic lactobacilli and fluoride dramatically reduces dental caries in children and adults [68]. Results from laboratory and animal model studies are promising; however, largescale, randomized clinical trials are still needed to support the utilization of probiotics as a safe and long-lasting treatment for dental caries.

Increasing dental biofilm $\mathrm{pH}$ is another ecological strategy to diminish the cariogenic profile of the microbial community. Alkali production (ammonia) in plaque results from the bacterial metabolism of urea and arginine provided in saliva [69]. High levels of urea and arginine or arginine-rich peptides in dental biofilm may be obtained by the introduction of genetically engineered, alkali-producing streptococci, or by prebiotics.

More specific therapies targeting $S$. mutans within the biofilm have also been developed, including specifically targeted antimicrobial peptides (STAMPs) and vaccines. A specific synthetic antimicrobial peptide, for instance the C16G2, has shown rapid bactericidal activity against S. mutans in vitro, not affecting other oral streptococci [70]. Moreover, biofilms treated with this peptide seem to resist recolonization by S. mutans [71].

Over decades, extensive research in animal models and small human trials have demonstrated the efficacy of immunization in inducing mucosal protective immunity against mutans streptococci, and reducing colonization and subsequent development of caries [72, 73]. More specifically, surface adhesins (AgI/II), glucosyltransferases, synthetic peptides, and the glucan-binding proteins of mutans streptococci administered by oral or intranasal immunization have demonstrated the induction of salivary S-IgA and circulating IgG antibodies. The anti-caries DNA vaccine encoding antigens of both $S$. mutans and $S$. sobrinus (pGJGAC/VAX) was also effective in reducing the levels of these species and dental caries in animal models [74]. Passive immunization with antibodies to mutans streptococci antigens has produced promising results, but because there is no induction of immunological memory, these antibodies need to be continuously provided to maintain protection over a prolonged time [72, 73]. General issues regarding caries vaccine development, including the risk/benefits, costs, target populations, and acceptance by the public and professionals, are still of concern.

Approaches that result in significant reduction or elimination of resident microorganisms (mutans streptococci) raise questions such as how long it would take for S. mutans to recolonize the oral microbiota, or what was the long-term effect of changing the normal microbiota. Significant advances in the understanding of the ecology of the cariogenic biofilm have been made, and alternative strategies for caries prevention and treatment are in progress. Until these therapies are proven to be safe and effective for use in humans, 
conventional methods such as mechanical removal of biofilm, restriction in sugar intake and continuous use of fluoride are sufficient prevention strategies against dental caries.

\section{Periodontopathogenic Biofilm}

Periodontal diseases are chronic oral diseases that are highly prevalent worldwide with a broad spectrum of clinical manifestations ranging from mild gingivitis to severe forms of periodontitis $[75,76]$. Chronic gingivitis is induced by dental biofilm and is characterized by marginal gingival inflammation without clinical or radiographic evidence of periodontal attachment loss. It is a reversible condition that can be easily treated and prevented. Periodontitis is a gingival inflammation with apical migration of the junctional epithelium over the root surface, which is followed by attachment loss and alveolar bone resorption. Periodontitis can be further classified mainly as chronic or aggressive periodontitis [75].

Virtually all forms of periodontal diseases are infectious diseases that result from dynamic interactions of the periodontopathogenic biofilm, innate and adaptive host immune responses, and behavioral, environmental and genetic susceptibility factors [77]. Thus, the persistence of a pathogenic periodontal microbiota is necessary but not sufficient for the establishment of periodontal diseases [78, 79]. Different from the cariogenic biofilm, the pathogenicity of periodontopathogenic biofilm is related to the predominance of bacterial products and components that will cause direct and indirect periodontal tissue destruction. Bacterial virulence factors induce host immune cells to produce inflammatory mediators that interfere with the connective and bone tissues, leading to periodontal breakdown. Therefore, periodontal breakdown is mainly caused by the host immunological response induced by specific pathogenic microbial communities [77-79].

Evidence of the key role of bacteria in the etiology of periodontal diseases was demonstrated by the classical study of experimental gingivitis [80]. A fundamental observation of this study was that everybody will, at some point, develop gingivitis if they do not clean their teeth. Another conclusion was that susceptibility to gingivitis may vary among subjects. Although experimental gingivitis studies reinforced the role of dental biofilm in the initiation of periodontal diseases, these findings brought out the non-specific plaque hypothesis which was based on the idea that any accumulation of dental plaque could lead to periodontal diseases [55]. It may be true for gingivitis but does not apply to periodontitis.

Over the years, bacterial etiology of periodontal diseases went through alternate phases of specificity and nonspecificity [81]. With the significant improvements in techniques associated with isolation, cultivation, and molecular identification of microorganisms, and in the understanding of the etiopathogenesis of periodontal diseases, a large number of species or bacterial communities associated with periodontal health and different types of periodontal diseases were described [25, 27, 28, 78]. This concept of pathogenic communities as the etiological entity of periodontal diseases was consolidated by the description of the five microbial complexes of the subgingival biofilm [78, $82 \bullet$ ]. A strong association between the orange and red complexes with clinical signs of periodontal inflammation and tissue destruction was demonstrated, whereas the blue, purple, and yellow complexes were associated with periodontal health. Moreover, it was shown that the establishment of the complexes follows a pattern of successive and hierarchical colonization, indicating specific relationships among species within and among complexes [82••]. Despite the general consensus that periodontal diseases have a polymicrobial etiology, until now only three species have been considered as putative periodontal pathogens: Aggregatibacter actinomycetemcomitans, Porphyromonas gingivalis and Tannerella forsythia [83, 84]. In chronic periodontitis, high proportions of the red and orange complexes are observed, while A. actinomycetemcomitans is a major pathogen associated with aggressive forms of periodontitis [83]. However, recent studies have shown that in addition to $A$. actinomycetemcomitans, aggressive periodontitis may be modulated by a consortia of pathogenic species [85-88]. Microorganisms associated with other infections in the human body, as well as novel potential pathogenic species, including not-yet-cultivated microorganisms, may also play a role in the initiation, progression, and/or severity of various forms of periodontal diseases [89-95].

The current view of periodontal microbiology is that in conditions of health the periodontal biofilm presents a very diverse microbiota composed mainly of resident and protective species. Shifts in the ecology of this biofilm may result in microbial dysbiosis, with a decrease in hostcompatible species and an increase in more pathogenic microorganisms [79, 96, 97]. Dysbiosis can be induced by various factors and conditions, which may trigger the host response and alter the periodontal microenvironment, favoring the overgrowth of periodontopathogenic species [96]. The exact mechanisms involved in shifts from a health-related commensal microbiota to a pathogenic microbiome in periodontal diseases remain unknown. Hopefully, future prospective microbiological studies will be able to identify novel bacterial biomarkers of health and disease which will allow us to detect subjects at risk of developing destructive periodontal disease, and to design more suitable therapies with the purpose of restoring the host-compatible resident microbiota [98]. 


\section{Biofilm Associated with Endodontic Infections}

The pulp is a sterile tissue and once microorganisms have access to it, an infectious process begins. In endodontic diseases, arrangements of bacteria colonizing the root canal system (RCS) as sessile biofilms can be seen adhered to root canal walls, inside isthmuses, ramifications, dentinal tubules, accessory and lateral canals, as well as on external root areas and even on filling materials $[99,100]$. The morphological structure of this biofilm may vary from case to case, and the reasons for this may be related to time of infection, type and availability of nutrients, and composition and function of the established microbiota [99]. Initial studies using microbial cultivation methods identified a limited number of microorganisms associated with endodontic infections, but the introduction of culture-independent techniques revealed a much more complex and diverse microbiota [99]. Primary endodontic infections are polimicrobial infections composed mainly of obligate anaerobes, with a high prevalence of members of the phyla Firmicutes and Bacteroidetes. Differences in composition are also observed along the root canal, with a higher microbial diversity in the apical region [101]. Survival of microorganisms in the apical RCS and/or outside the apical foramen may lead to treatment failure and the establishment of persistent infections. Compared with primary infections, the microbiota associated with endodontic failure presents a narrower range of bacterial species, and is basically composed of Gram-positive facultative anaerobes, in particular Enterococcus faecalis [102]. E. faecalis became the most studied species in endodontics because of its innate resistance, ability to survive in an inhospitable environment, and ability to form biofilm. The efficacy of root canal medicaments, irrigants, obturation materials, and alternative endodontic therapies has been extensively evaluated using $E$. faecalis biofilm as a model $[103,104]$. In persistent periapical infections, analysis of the area around the apical foramen has demonstrated the presence of extraradicular biofilm with amorphous extracellular material and multiple bacterial species [105].

The success of endodontic treatment is dependent upon several factors, including efficient removal of bacterial biofilms and their byproducts from the RCS. The main challenge in root canal disinfection is the root canal anatomy. The complexity of the RCS, especially at the apical area, with the presence of accessory canals, lateral canals, transverse anastomosis, and apical ramification, makes the complete elimination of microorganisms from this system impossible, regardless of the instrument, technique, or root canal medicaments utilized [106]. However, significant reductions in bacterial levels (and not necessarily complete elimination of bacteria), proper shaping, and obturation techniques may provide a favorable environment for apical healing. Over the years, extensive research has generated new instruments, medicaments, and therapies focused on improving endodontic treatment. A new device that deserves attention combines instrumentation and irrigation simultaneously-the SelfAdjusting File System or SAF. This system is based on a single file, a hollow reciprocating nickel-titanium instrument that can adapt to the cross-section of the root canal. The void design of the instrument enables a constant flow of irrigant through the full length of the canal during the procedure, and is activated by vibration. This allows better and more efficient shaping, cleaning, and removal of bacterial biofilm, even inside grooves, when compared with hand and rotary nickeltitanium [107, 108].

Endodontic irrigants are routinely used as adjuncts to mechanical treatment, acting as antimicrobials and chelating agents. Moreover, the fluid dynamic of irrigation generates a flushing action capable of mechanically disrupting the bacterial biofilm. Sodium hypochlorite is the most commonly used irrigant due to its wide spectrum of antimicrobial properties, and ability to dissolve organic material [109]. Different techniques have been developed to improve the antimicrobial efficacy and fluid dynamic performance of irrigants. The EndoVac $^{\circledR}$ system is an apical negative pressure irrigation device that was developed to deliver irrigating solution to the apical end of the RCS, and remove debris at the apex without forcing the solution to the periapical tissues [110]. In a recent ex vivo study, this system demonstrated considerable antimicrobial efficacy against $E$. faecalis biofilm [104]. Ultrasonic and sonic agitation can also be used as a means of increasing the effectiveness of chemomechanical debridement and disrupt bacterial communities in comparison to conventional irrigation [111].

Another effective strategy to improve conventional endodontic treatment is photodynamic therapy (PDT) [112]. PDT is based on the use of a non-toxic photosensitizer activated by a resonant light source of an appropriate wavelength in the presence of oxygen. The action of the light on the photosensitizer leads to the production of highly reactive and cytotoxic oxygen species to bacterial cells [112]. PDT presents several advantages, such as safety to human tissues, ability to eliminate pathogens within biofilms, and simple application, among others. Data from in vitro studies and few clinical trials have indicated that PDT is an effective approach for inactivation of intracanal biofilms and improvement of RCS disinfection [112].

The use of nanoparticles as potential antibacterial agents has also been tested. Nanoparticles associated with chitosan (CS-np) and zinc oxide (ZnO-np) have demonstrated high efficacy in disorganizing the biofilm structure and retaining the antibacterial property for a long period of time [113]. In addition, combinations of medicaments and/or techniques, including new classes of photosensitizers associated with nanoparticles and PDT, have been proposed. This association seems to offer physicochemical advantages, such as selectivity of bacterial cells, increased affinity of the drug to bacterial 
cell membrane, stability of the photosensitizer inside the cell, deeper penetration into the biofilm structure, and controlled release of oxygen species [114].

Despite all these new strategies that are under development for improving endodontic therapy, appropriate conventional chemomechanical debridement of the RCS is the key factor for treatment success. Furthermore, the additional benefits of these innovative instruments and techniques need to be proven by large-scale, randomized clinical trials, which are still very limited.

\section{Fungal Biofilm Associated with Oral Infections}

Although bacteria comprise the most predominant group of microorganisms of the oral microbiota, a large number of diverse fungi have been shown to colonize the oral cavity of healthy individuals [115]. Despite that, knowledge of the role of oral mycobiome on oral health is still limited. Fungi are eukaryotic free-living microorganisms capable of causing a wide spectrum of infections in humans, including superficial, subcutaneous, or systemic mycoses. Fungal infections are usually acquired by inhalation or traumatic implantation from an exogenous source, or as a result of a dysbiosis of the resident microbiota associated with the persistent use of immunosuppressive drugs and broad-spectrum antibiotics, as well as with immune deficiencies, malignancies, smoking, nutritional disorders, and/or diabetes [116]. Oral candidiasis is the most common fungal infection that affects the oral mucosa. Candida species, particularly Candida albicans, are usually commensal microorganisms detected in up to $75 \%$ of the oral cavity of healthy individuals. However, in certain conditions these dimorphic fungi may become virulent and cause disease, including pseudomembranous, erythematous or hyperplasic candidiasis, angular cheilitis, denture stomatitis, and median rhomboid glossitis, among others [116]. In addition to Candida, several other fungi have been identified in the oral microbiota, including non-culturable fungi [115]. Noncandidal oral infections include aspergillosis, cryptococcosis, histoplasmosis, blastomycosis, paracoccidioidomycosis, and zygomycosis (mucormycosis). Oral lesions caused by these deep fungal infections are characterized by chronic deep ulcers which may disseminate to paranasal sinuses, orbit, cranial base, and respiratory tract, usually in debilitated patients [117].

Virulence of fungi is associated with the presence of cellwall components (mannose, mannoprotein, and saccharins) that promote adhesion to epithelial cells, persistence within cells, germ tube formation, production of proteinases and fungal toxins, biofilm formation, and dimorphism and cocolonization with certain bacterial species [118, 119]. Of interest, fungal biofilms are critical for the development of clinical infection. Fungal biofilm formation involves adhesion to biotic (oral mucosa) and/or abiotic (prosthesis) surfaces, proliferation of yeast cells, hyphal formation and production of extracellular matrix [118]. In fungal infections, the complex structure of biofilms results in increased resistance to antifungal drugs, leading to therapeutic failure. Drug binding by extracellular matrix, production of highly drug-tolerant persister cells, upregulation of transcriptional factors related to hyphal formation, adherence, and multidrug resistance, as well as cell-wall synthesis and efflux pumps, are some of the fungal biofilm features involved in increased resistance to antifungal drugs [118]. Resistance in fungi poses a serious threat to human health worldwide since there are a much more limited number of antifungal agents (azoles, polyenes, echinocandins) available for mycoses treatment in comparison to antibiotics.

More recently, fungal-bacterial interactions and their role in oral health and disease have been emphasized [120]. Evidence indicate that overgrowth of Candida species is related to a disruption of the bacterial microbiome caused, for instance, by antibiotic intake [121]. Other studies have shown synergistic associations between the oral acidogenic microbiota and Candida spp. [122]. In vitro and animal models have demonstrated that co-infection of Mitis group streptococci and C. albicans is associated with oral candidiasis, whereas Candida-S. mutans may play a significant role in the pathogenesis of dental caries [120,123]. In fact, the presence of C. albicans increases biofilm formation by $S$. mutans [123]. Moreover, severe mucosal infection and inflammation is observed when $S$. oralis colonizes the oral mucosa together with $C$. albicans [120]. These data indicate that knowledge of fungal-bacterial interactions is also crucial for understanding the pathogenesis of oral infections, and designing suitable diagnostic and therapeutic strategies for the management of these biofilm-related diseases.

\section{Conclusion and Future Perspectives}

There is no doubt that we now have a much deeper understanding of the composition and function of the biofilm associated with most oral infections than we had a few decades ago; however, there still much to be learned. Oral biofilms are sophisticated structures developed by microorganisms for survival, and virulence is usually increased within these organized communities. However, biofilms may have different levels of pathogenicity. Currently, the concept that oral diseases are caused by complex multispecies biofilms, and not by single pathogens, is accepted. It is also common sense that oral diseases manifest as a result of an unbalance in the dynamic relationships among the biofilm, host, and microenvironment. Therefore, efforts have been made to improve our knowledge regarding the composition and physiology of hostcompatible health-associated biofilms in order for us to 
comprehend the changes that lead to disease. Conceivably, much of what we do now in terms of therapy will be maintained, although with less empiricism and more specificity. In contrast, significant changes in how we deal with these infections may happen in the very near future. In fact, ecological therapeutic strategies such as prebiotics and probiotics have been developed to interfere with biofilm formation, to disrupt environmental conditions favorable to oral biofilm pathogenicity, and to improve host immunity for the re-establishment of oral homeostasis. Until evidence regarding these alternative strategies is scientifically proven to be effective, treatment of biofilm-associated oral diseases will rely on unspecific mechanical methods for preventing biofilm formation and disorganizing the established oral biofilm.

\section{Compliance with Ethics Guidelines}

Conflict of Interest Ana Paula Vieira Colombo, Renata Martins do Souto, Carina Maciel da Silva-Boghossian, Rachel Miranda, and Talita Gomes Baêta Lourenço declare that they have no conflict of interest.

Human and Animal Rights and Informed Consent This article does not contain any studies with human or animal subjects performed by any of the authors.

\section{References}

Papers of particular interest have been highlighted as:

•- Of major importance

1. Whitman WB, Coleman DC, Wiebe WJ. Prokaryotes: the unseen majority. Proc Natl Acad Sci U S A. 1998;95:6578-83.

2. Ley RE, Lozupone CA, Hamady M, Knight R, Gordon JI. Worlds within worlds: evolution of the vertebrate gut microbiota. Nat Rev Microbiol. 2008;6:776-88.

3.• Human Microbiome Project Consortium. Structure, function and diversity of the healthy human microbiome. Nature. 2012;486: 207-14. This paper shows the high diversity and abundance of the microbiota colonizing clinically relevant body habitats of healthy individuals. In contrast, metabolic pathways were stable among individuals.

4. Turnbaugh PJ, Ley RE, Hamady M. The human microbiome project. Nature. 2007;449:804-10

5. Ley RE, Turnbaugh PJ, Klein S, Gordon JI. Microbial ecology: human gut microbes associated with obesity. Nature. 2006;444: 1022-3.

6. Stappenbeck TS, Hooper LV, Gordon JI. Developmental regulation of intestinal angiogenesis by indigenous microbes via paneth cells. Proc Natl Acad Sci U S A. 2002;99:15451-5.

7. $\mathrm{Xu}$ J, Gordon JI. Inaugural article: honor thy symbionts. Proc Natl Acad Sci U S A. 2003;100:10452-9.

8. Mazmanian SK, Liu CH, Tzianabos AO, Kasper DL. An immunomodulatory molecule of symbiotic bacteria directs maturation of the host immune system. Cell. 2005;122:107-18.

9. Badger JH, Ng PC, Venter JC. The human genome, microbiomes, and disease. In: Nelson KE, editor. Metagenomics of the human body. New York: Springer Science Business Media; 2011. p. 1-14. XVII.
10. Cho I, Blaser MJ. The human microbiome: at the interface of health and disease. Nat Rev Genet. 2012;13:260-70.

11. Sonnenburg JL, Fischbach MA. Community health care: therapeutic opportunities in the human microbiome. Sci Transl Med. 2011;3:78ps12.

12. Costello EK, Louber CL, Hamady M, Fierer N, Gordon JI, Knight R. Bacterial community variation in human body habitats across space and time. Science. 2009;326:1694-7.

13. Holmes E, Li JJ, Athanasiou T, Ashrafian H, Nicholson JK. Understanding the role of gut microbiome-host metabolic signal disruption in health and disease. Trends Microbiol. 2011;19:349-59.

14. Wang Z. Gut flora metabolism of phosphatidylcholine promotes cardiovascular disease. Nature. 2011;472:57-63.

15. Peek R, Blaser MJ. Helicobacter pylori and gastrointestinal tract adenocarcinomas. Nat Rev Cancer. 2002;2:28-37.

16. Reid G, Howard J, Gan BS. Can bacterial interference prevent infection? Trends Microbiol. 2001;9:424-8.

17. Petersen PE, Bourgeois D, Ogawa H, Estupinan-Day S, Ndaye C. The global burden of oral diseases and risks to oral health. Bull World Health Organ. 2005;83:661-9.

18.• Dewhirst FE, Chen T, Izard J, Paster BJ, Tanner ACR, Yu W, et al. The human oral microbiome. J Bacteriol. 2010;192:5002-17. This paper provides the first curated description of the human oral microbiome through the phylogeny-based Human Oral Microbiome Database (HOMD).

19. Zarco MF, Vess TJ, Ginsburg GS. The oral microbiome in health and disease and the potential impact on personalized dental medicine. Oral Dis. 2012;18:109-20.

20. Zaura E, Keijser BJ, Huse SM, Crielaard W. Defining the healthy "core microbiome" of oral microbial communities. BMC Microbiol. 2009;9:259.

21. Jenkinson HF. Beyond the oral microbiome. Environ Microbiol. 2011;13:3077-87.

22. Paster BJ, Dewhirst FE. Molecular microbial diagnosis Periodontol 2000. 2009;51:38-44.

23. Chen T, Yu W, Izard J, Baranova OV, Lakshmanan A, Dewhirst FE. The human oral microbiome database: a web accessible resource for investigating oral microbe taxonomic and genomic information. Database (Oxford). 2010;2010:baq013. doi: 10 . 1093/database/baq013

24. Moore WEC, Moore LH. The bacteria of periodontal diseases Periodontol 2000. 1994;5:66-77.

25. Paster BJ, Boches SK, Galvin JL, Ericson RE, Lau CN, Levanos $\mathrm{VA}$, et al. Bacterial diversity in human subgingival plaque. $\mathrm{J}$ Bacteriol. 2001;183:3770-83.

26. Xu X, He J, Xue J, Wang Y, Li K, Zhang K, et al. Oral cavity contains distinct niches with dynamic microbial communities. Environ Microbiol. doi: 10.1111/1462-2920.12502.

27. Aas JA, Paster BJ, Stokes LN, Olsen I, Dewhirst FE. Defining the normal bacteria flora of the oral cavity. J Clin Microbiol. 2005;43: 5721-32.

28. Socransky SS, Haffajee AD. Dental biofilms: difficult therapeutic targets. Periodontol 2000. 2002;28:12-55.

29. Costerton JW, Geesey GG, Cheng KJ. How bacteria stick. Sci Am. 1978;238:86-95.

30. Donlan RM, Costerton JW. Biofilms: survival mechanisms of clinically relevant microorganisms. Clin Microbiol Rev. 2002;15:167-93.

31. Flemming HC, Wingender J. Relevance of microbial extracellular polymeric substances (EPSs). Part I: structural and ecological aspects. Water Sci Technol. 2001;43:1-8.

32. Marsh PD, Moter A, Devine DA. Dental plaque biofilms: communities, conflict and control. Periodontol 2000. 2011;55:16-35.

33. Busscher HJ, van der Mei HC. Physico-chemical interactions in initial microbial adhesion and relevance for biofilm formation. Adv Dent Res. 1997;11:24-32. 
34. Haffajee AD, Socransky SS, Patel MR, Song X. Microbial complexes in supragingival plaque. Oral Microbiol Immunol. 2008;23:196-205.

35. Kuboniwa M, Lamont RJ. Subgingival biofilm formation. Periodontol 2000. 2010;52:38-52.

36. Kolenbrander PE, Andersen RN, Blehert DS, Egland PG, Foster JS, Palmer Jr RJ. Communication among oral bacteria. Microbiol Mol Biol Rev. 2002;66:486-505.

37. Chalmers NI, Palmer RJ, Cisar JO, Kolenbrander PE. Characterization of a Streptococcus sp.-Veillonella sp. community micromanipulated from dental plaque. J Bacteriol. 2008;190: 8145-54.

38. Prosser JI. Quorum sensing in biofilms. In: Newman HN, Wilson M, editors. Dental plaque revisited. Cardiff: Bioline; 1999. p. 7988.

39. McNab R, Ford SK, El-Sabaeny A, Barbieri B, Cook GS, Lamont RJ. LuxS-based signaling in Streptococcus gordonii: autoinducer 2 controls carbohydrate metabolism and biofilm formation with Porphyromonas gingivalis. J Bacteriol. 2003;185:274-84.

40. LeBlanc DJ, Hawley RJ, Lee LN, St Martin EJ. "Conjugal" transfer of plasmid DNA among oral streptococci. Proc Natl Acad Sci U S A. 1978;75:3484-7.

41. Sedgley CM, Lee EH, Martin MJ, Flannagan SE. Antibiotic resistance gene transfer between Streptococcus gordonii and Enterococcus faecalis in root canals of teeth ex vivo. J Endod. 2008;34:570-4.

42. Selwitz RH, Ismail AI, Pitts NB. Dental caries. Lancet. 2007;369: $51-9$.

43. Low W, Tan S, Schwartz S. The effect of severe caries on the quality of life in young children. Pediatr Dent. 1999;21:325-6.

44. Bagramian RA, Garcia-Godoy F, Volpe AR. The global increase in dental caries: a pending public health crisis. Am J Dent. 2009;22:38 .

45. Keyes PH. Infections and transmissible nature of experimental dental caries. Arch Oral Biol. 1960;1:304-20.

46. Caufield PW, Cutter GR, Dasanayake AP. Initial acquisition of mutans streptococci in infants: evidence for a discrete window of infectivity. J Dent Res. 1993;72:37-45.

47. Mattos-Graner R, Li Y, Caufield PW, Duncan M, Smith D. Genotypic diversity of mutans streptococci in Brasilian nursery children suggests horizontal transmission. J Clin Microbiol. 2001;39:2313-6.

48. Berkowitz RJ. Mutans streptococci acquisition and transmission. Pediatr Dent. 2006;2:106-9.

49. Fejerskov O. Changing paradigms in concepts on dental caries: consequences for oral health care. Caries Res. 2004;38:182-91.

50. van Ruyven FOJ, Lingstrom P, van Houte J, Kent R. Relationship among mutans streptococci, "low-pH" bacteria, and iodophilic polysaccharide-producing bacteria in dental plaque and early enamel caries in humans. J Dent Res. 2000;79:778-84.

51. Köhler B, Andréen I. Influence of caries-preventive measures in mothers on cariogenic bacteria and caries experience in their children. Arch Oral Biol. 1994;39:907-11.

52. Struzycka I. The oral microbiome in dental caries. Pol J Microbiol. 2014;63:127-35.

53. Matee MI, Mikx FH, de Soet JS, Maselle SY, de Graaff J, van Palenstein Helderman WH. Mutans streptococci in caries-active and caries-free infants in Tanzania. Oral Microbiol Immunol. 1993;8:322-4.

54. Theilade E. The non-specific theory in microbial etiology of inflammatory periodontal diseases. J Clin Periodontol. 1986;13:905-11.

55. Loesche WJ. The specific plaque hypothesis and the antimicrobial treatment of periodontal disease. Dent Updat. 1992;19:68-74.

56. van Houte J. Role of micro-organisms in caries etiology. J Dent Res. 1994;73:672-81.
57. Byun R, Nadkarni MA, Chhour KL, Martin FE, Jacques NA, Hunter N. Quantitative analysis of diverse Lactobacillus species present in advanced dental caries. J Clin Microbiol. 2004;42:3128-36.

58. Zambon JJ, Kasprzak SA. The microbiology and histopathology of human root caries. Am J Dent. 1995;8:323-8.

59. Chhour KL, Nadkarni MA, Byun R, Martin FE, Jacques NA, Hunter N. Molecular analysis of microbial diversity in advanced caries. J Clin Microbiol. 2005;43:843-9.

60. Aas JA, Griffen AL, Dardis SR, Lee AM, Olsen I, Dewhirst FE, et al. Bacteria of dental caries in primary and permanent teeth in children and young adults. J Clin Microbiol. 2008;46:1407-17.

61. Preza D, Olsen I, Aas JA, Willumsen T, Grinde B, Paster BJ. Bacterial profiles of root caries in elderly patients. J Clin Microbiol. 2008;46:2015-21.

62. Jiang $\mathrm{W}$, Ling $\mathrm{Z}$, Lin $\mathrm{X}$, Chen $\mathrm{Y}$, Zhang J, Yu J, et al. Pyrosequencing analysis of oral microbiota shifting in various caries states in childhood. Microb Ecol. 2014;67:962-9.

63. Marsh PD. Are dental diseases examples of ecological catastrophes? Microbiology. 2003;149:279-94.

64. Anusavice KJ. Present and future approaches for the control of caries. J Dent Educ. 2005;69:538-54.

65. Eckert R, Sullivan R, Shi W. Targeted antimicrobial treatment to re-establish a healthy microbial flora for long-term protection. Adv Dent Res. 2012;22:94-7.

66. Hillman JD, Brooks TA, Michalek SM, Harmon CC, Snoep JL, van der Weijden CC. Construction and characterization of an effector strain of Streptococcus mutans for replacement therapy of dental caries. Infect Immun. 2000;68:543-9.

67. de Vrese M, Schrezenmeir J. Probiotics, prebiotics, and synbiotics. Adv Biochem Eng Biotechnol. 2008;111:1-66.

68. Petersson LG, Magnusson K, Hakestam U, Baigi A, Twetman S. Reversal of primary root caries lesions after daily intake of milk supplemented with fluoride and probiotic lactobacilli in older adults. Acta Odontol Scand. 2011;69:321-7.

69. Burne RA, Marquis RE. Alkali production by oral bacteria and protection against dental caries. FEMS Microbiol Lett. 2000;193:1-6.

70. Kaplan CW, Sim JH, Shah KR, Kolesnikova A, Shi W, Eckert R. Selective membrane disruption: the mode of action of C16G2, a specifically-targeted antimicrobial peptide. Antimicrob Agents Chemother. 2011;55:3446-52.

71. Li LN, Guo LH, Lux R, Eckert R, Yarbrough D, He J, et al. Targeted antimicrobial therapy against Streptococcus mutans establishes protective non-cariogenic oral biofilms and reduces subsequent infection. Int J Oral Sci. 2010;2:66-73.

72. Smith DJ. Caries vaccine for the twenty-first century. J Dent Educ. 2003;67:1130-9.

73. Gambhir RS, Singh S, Singh G, Singh R, Nanda T, Kakar H. Vaccine against dental caries: an urgent need. J Vaccines Vaccin. 2012;3:136.

74. Niu Y, Sun J, Fan M, Xu QA, Guo J, Jia R, et al. Construction of a new fusion anti-caries DNA vaccine. J Dent Res. 2009;88:455-60.

75. Armitage GC. Development of a classification system for periodontal diseases and conditions. Ann Periodontol. 1999;4:1-6.

76. Marcenes W, Kassebaum NJ, Bernabé E, Flaxman A, Naghavi M, Lopez A, et al. Global burden of oral conditions in 1990-2010: a systematic analysis. J Dent Res. 2013;92(7):592-7.

77. Page RC, Kornman KS. The pathogenesis of human periodontitis: an introduction. Periodontol 2000. 1997;14:9-11.

78. Socransky SS, Haffajee AD. Periodontal microbial ecology. Periodontol 2000. 2005;38:135-87.

79. Jiao Y, Hasegawa M, Inohara N. The role of oral pathobionts in dysbiosis during periodontitis development. J Dent Res. 2014;93: 539-46. 
80. Loe H, Theilade E, Jensen SB. Experimental gingivitis in man. J Periodontol. 1965;36:177-87.

81. Haffajee AD, Socransky SS. Microbial etiological agents of destructive periodontal diseases. Periodontol 2000. 1994;5:78-111.

82.• Socransky SS, Haffajee AD, Cugini MA, Smith C, Kent Jr RL. Microbial complexes in subgingival plaque. J Clin Periodontol. 1998;25:134-44. This is a classical study that reports on the existence of five major microbial complexes of the subgingival microbiota related to periodontal health and disease.

83. Slots J, Ting M. Actinobacillus actinomycetemcomitans and Porphyromonas gingivalis in human periodontal disease: occurrence and treatment. Periodontol 2000. 1999;20:82-121.

84. Holt SC, Ebersole JL. Porphyromonas gingivalis, Treponema denticola, and Tannerella forsythia: the "red complex", a prototype polybacterial pathogenic consortium in periodontitis. Periodontol 2000. 2005;38:72-122.

85. da Silva-Boghossian CM, do Souto RM, Luiz RR, Colombo AP. Association of red complex, A. actinomycetemcomitans and nonoral bacteria with periodontal diseases. Arch Oral Biol. 2011;56: 899-906.

86. Heller D, Silva-Boghossian CM, do Souto RM, Colombo AP. Subgingival microbial profiles of generalized aggressive and chronic periodontal diseases. Arch Oral Biol. 2012;57:973-80.

87. Fine DH, Markowitz K, Fairlie K, Tischio-Bereski D, Ferrendiz J, Furgang D, et al. A consortium of Aggregatibacter actinomycetemcomitans (Aa), Streptococcus parasanguinis and Filifactor alocis are present in sites prior to bone loss in a longitudinal study of localized aggressive periodontitis. J Clin Microbiol. 2013;51:2850-61.

88. Lourenço TG, Heller D, Silva-Boghossian CM, Cotton SL, Paster BJ, Colombo AP. Microbial signature profiles of periodontally healthy and diseased patients. J Clin Periodontol. 2014;41(11): 1027-36.

89. Kumar PS, Griffen AL, Moeschberger ML, Leys EJ. Identification of candidate periodontal pathogens and beneficial species by quantitative 16S clonal analysis. J Clin Microbiol. 2005;43: 3944-55.

90. Colombo AP, Teles RP, Torres MC, Souto R, Rosalém WJ, Mendes $\mathrm{MC}$, et al. Subgingival microbiota of Brazilian subjects with untreated chronic periodontitis. J Periodontol. 2002;73:360-9.

91. Colombo AP, Boches SK, Cotton SL, Goodson JM, Kent R, Haffajee AD, et al. Comparisons of subgingival microbial profiles of refractory periodontitis, severe periodontitis, and periodontal health using the human oral microbe identification microarray. J Periodontol. 2009;80:1421-32.

92. Botero JE, Contreras A, Lafaurie G, Jaramillo A, Betancourt M, Arce RM. Occurrence of periodontopathic and superinfecting bacteria in chronic and aggressive periodontitis subjects in a Colombian population. J Clin Periodontol. 2007;78:696-704.

93. Souto R, de Andrade AFB, Uzeda M, Colombo APV. Prevalence of "non-oral" pathogenic bacteria in subgingival biofilm of subjects with chronic periodontitis. Braz J Microbiol. 2006;37:208-15.

94. Souto R, Silva-Boghossian CM, Colombo APV. Prevalence of Pseudomonas aeruginosa and Acinetobacter spp. in subgingival biofilm and saliva of subjects with chronic periodontal infection. Braz J Microbiol. 2014;45:495-501.

95. Pérez-Chaparro PJ, Gonçalves C, Figueiredo LC, Faveri M, Lobão E, Tamashiro N, et al. Newly identified pathogens associated with periodontitis: a systematic review. J Dent Res. 2014;93:846-58.

96. Bartold PM, Van Dyke TE. Periodontitis: a host-mediated disruption of microbial homeostasis. Unlearning learned concepts. Periodontol 2000. 2013;62:203-17.

97. Hajishengallis G, Lamont RJ. Beyond the red complex and into more complexity: the polymicrobial synergy and dysbiosis (PSD) model of periodontal disease etiology. Mol Oral Microbiol. 2012;27(6):409-19.

98. Charalampakis G, Dahlén G, Carlén A, Leonhardt A. Bacterial markers vs. clinical markers to predict progression of chronic periodontitis: a 2-yr prospective observational study. Eur J Oral Sci. 2013;121:394-402.

99. Ricucci D, Siqueira JF. Biofilms and apical periodontitis: study of prevalence and association with clinical and histopathologic findings. J Endod. 2010;36:1277-88.

100. Baldasso FER, Stürmer CP, Luisi SB, Petruzzi MNMR, Scarparo RK, Figueiredo JAP. Microflora associated with primary endodontic infections: correlations among SEM evaluation, clinical features, and radiographic findings. Micros Res Tech. 2012;75: $1557-63$.

101. Özok AR, Persoon IF, Huse SM, Keijser BJF, Wesselink PR, Crielaard W, et al. Ecology of the microbiome of the infected root canal system: a comparison between apical and coronal root segments. Int Endod J. 2012;45:530-41.

102. Murad CF, Sassone LM, Faveri M, Hirata R, Figueiredo L, Feres M. Microbial diversity in persistent root canal infections investigated by checkerboard DNA-DNA hybridization. J Endod. 2014;40:899.906.

103. Arias-Moliz MT, Ferrer-Luque CM, Espigares-García M, Baca P. Enterococcus faecalis biofilms eradication by root canal irrigants. J Endod. 2009;35:711-4.

104. Miranda RG, Santos EB, Souto RM, Gusman H, Colombo APV. Ex vivo antimicrobial efficacy of the EndoVac ${ }^{\mathbb{R}}$ system plus photodynamic therapy associated with calcium hydroxide against intracanal Enterococcus faecalis. Int Endod J. 2013;46:499-505.

105. Wang J, Jiang Y, Chen W, Zhu C, Liang J. Bacterial flora and extraradicular biofilm associated with the apical segment of teeth with post-treatment. J Endod. 2012;38:954-9.

106. Peters OA, Laib A, Rüegsegger P, Barbakow F. Threedimensional analysis of root canal geometry by high-resolution computed tomography. J Dent Res. 2000;79:1405-9.

107. Lin J, Shen Y, Haapasalo M. A comparative study of biofilm removal with hand, rotary nockel-titanium, and self-adjusting file instrumentation using a novel in vitro biofilm model. J Endod. 2013;39:658-63.

108. Metzger Z. The self-adjusting file (SAF) system: an evidencebased update. J Conserv Dent. 2014;17:401-19.

109. Harrison JW, Hand RE. The effect of dilution and organic matter in the anti-bacterial property of $5.25 \%$ sodium hypochlorite. J Endod. 1981;7:128-32.

110. Mitchell RP, Baumgartner JC, Sedgley CM. Apical extrusion of sodium hypochlorite using different root canal irrigation systems. J Endod. 2011;37:1677-81.

111. Townsend C, Maki J. An in vitro comparison of new irrigation and agitation techniques to ultrasonic agitation in removing bacteria from a simulated root canal. J Endod. 2009;35:1040-3.

112. Chrepa V, Kotsakis GA, Pagonis TC, Hargreaves KM. The effect of photodynamic therapy in root canal disinfection: a systematic review. J Endod. 2014;40:891-8.

113. Shrestha A, Zhilong S, Gee NK, Kishen A. Nanoparticulates for antibiofilm treatment and effect aging on its antibacterial activity. J Endod. 2010;36:1030-5.

114. Veerapandian M, Yun K. Functionalization of biomolecules on nanoparticles: specialized for antibacterial applications. Appl Microbiol Biotechnol. 2011;90:1655-67.

115. Ghannoum MA, Jurevic RJ, Mukherjee PK, Cui F, Sikaroodi M, Naqvi A, et al. Characterization of the oral fungal microbiome (mycobiome) in healthy individuals. PLoS Pathog. 2010;6(1): e1000713.

116. Muzyka BC, Epifanio RN. Update on oral fungal infections. Dent Clin N Am. 2013;57(4):561-81. 
117. Iatta R, Napoli C, Borghi E, Montagna MT. Rare mycoses of the oral cavity: a literature epidemiologic review. Oral Surg Oral Med Oral Pathol Oral Radiol Endod. 2009;108(5):647-55.

118. Fanning S, Mitchell AP. Fungal biofilms. PLoS Pathog. 2012;8(4): e1002585.

119. Karkowska-Kuleta J, Rapala-Kozik M, Kozik A. Fungi pathogenic to humans: molecular bases of virulence of Candida albicans, Cryptococcus neoformans and Aspergillus fumigatus. Acta Biochim Pol. 2009;56(2):211-24

120. Diaz PI, Strausbaugh LD, Dongari-Bagtzoglou A. Fungalbacterial interactions and their relevance to oral health: linking the clinic and the bench. Front Cell Infect Microbiol. 2014;4:101.
121. Maraki S, Margioris AN, Orfanoudaki E. TselentisY, Koumantakis E, Kontoyiannis DP, et al. Effects of doxycycline, metronidazole and their combination on Candida species colonization of the human oropharynx, intestinal lumen and vagina. $\mathrm{J}$ Chemother. 2003;15:369-73.

122. Kraneveld EA, Buijs MJ, Bonder MJ, Visser M, Keijser BJ, Crielaard W, et al. The relation between oral Candida load and bacterial microbiome profiles in Dutch older adults. PLoS One. 2012;7:e42770.

123. Falsetta ML, Klein MI, Colonne PM, Scott-Anne K, Gregoire S, Pai $\mathrm{CH}$, et al. Symbiotic relationship between Streptococcus mutans and Candida albicans synergizes the virulence of plaquebiofilms in vivo. Infect Immun. 2014;82:1968-81. 